Cuestiones de filosofía

ISSN: 0123-5095

Vol. 1 - No. 17

Año 2015

pp. 76-103

\title{
LA CRISIS DE LA RAZÓN: DE LA FILOSOFÍA DE LA CONCIENCIA A LA FILOSOFÍA DEL LENGUAJE
}

\author{
The Reason Crisis: \\ From the Philosophy of Consciousness \\ to the Philosophy of Language
}

Carlos Eduardo Rojas-Rojas

carlos.rojas_ro@ucaldas.edu.co

Universidad de Caldas (Colombia)

Fecha de recepción: 1/11/ 2014

Fecha de evaluación: 14/02/2015

Fecha de aprobación: 11/09/2015

\section{Resumen}

El escrito ofrece elementos de juicio para sustentar que la crisis de la razón, especialmente vivida durante el siglo XX, no puede ser explicada satisfactoriamente desde las ciencias sociales que se fundamenten en el paradigma de la filosofía de la conciencia, y que, en su lugar, es posible explorar comprensiones más adecuadas desde las opciones que abre la filosofía del lenguaje. Inicia el artículo con el diagnóstico que realizó Husserl en el período de entre guerras; luego, presenta los esfuerzos explicativos realizados en dos momentos distintos de la teoría crítica, primero, con G. Lukács, y luego, con T. Adorno y M. Horkheimer; finalmente, presenta a grandes rasgos la propuesta que ofrece J. Habermas en su Teoría de la acción comunicativa.

* Sociólogo, Magíster en Filosofía, Doctorando en Estudios Territoriales, profesor asociado Universidad de Caldas, coordinador del grupo de investigación Idacanzás: previendo las mudanzas de los tiempos, carlos.rojas_ro@ucaldas.edu.co 
En el escrito, el autor recoge, sistematiza y unifica elaboraciones que ha realizado en sus cursos de métodos cualitativos de investigación y de teorías sociológicas, las cuales han orientado las investigaciones que ha realizado en la última década, así como trabajos de grado de estudiantes de Trabajo Social, Antropología y Sociología, de la Universidad de Caldas.

Palabras clave: Crisis de la razón, Filosofía de la conciencia, Filosofía del lenguaje, Epistemología.

\begin{abstract}
This paper offers evidence to support the idea that the crisis of reason, especially during the twentieth century, can not be explained satisfactory from the social sciences that are based on the philosophycal paradigm of consciousness and that, instead, it is possible to explore some more appropriate understandings from the options opened by the language philosophy-. It starts with the diagnosis made by Husserl in the interwar period, then presents the explanatory efforts at two different times of the critical theory, first with G. Lukács and then T. Adorno and M. Horkheimer, to finally present roughly the proposal offered by J. Habermas in his Theory of the Communicative Action.
\end{abstract}

In this article the author collects, systematizes and unifies some works that has achieved, in his courses with qualitative research methods and sociological theories, that have guided the research carried out in the last decade and which he has participated, in some undergraduate works, of students in Social Work, Anthropology and Sociology at the University of Caldas, Departament of Colombia.

Keywords: Crisis of Reason, Philosophy of Consciousness, Philosophy of Language, Epistemology.

\title{
INTRODUCCIÓN
}

En mayo de 1935, el filósofo austriaco Edmund Husserl (1859-1938) ofreció una conferencia en Viena en la que afirmó que Europa estaba enferma -en crisis-; se preguntó si acaso no hacía falta algo así como una medicina social, y, rápidamente, 
transformó el interrogante para indagar si esta comprensión de la ciencia moderna, además de equívoca, sería corresponsable de tales padecimientos; respondió:

En efecto, ésta es mi convicción, y asimismo espero mostrar con ello cómo se halla también aquí una fuente esencial de la naturalidad con la que el hombre de ciencia moderno ni siquiera cree digna de considerar la posibilidad de la fundamentación de una ciencia acerca del espíritu puramente cerrada en sí y universal, a la que, de tal modo, niega rotundamente (1935, p. 138).

El diagnóstico corresponde a un período en el que aún no logran superarse los rigores de la guerra y se advierten ya los preparativos para una nueva conflagración mundial que Husserl no alcanzará a presenciar, pero sía pronosticar, en la que se hará más que evidente cómo la ciencia se ha puesto al servicio de la barbarie y la destrucción humana. No obstante, el problema no es la utilización de la ciencia, sino si ella misma es uno de los factores explicativos, si es corresponsable de la barbarie. Husserl encuentra que ello es así, en tanto que los científicos asumen su oficio de manera naturalizada, es decir, dogmática. Embelesados con la consecución de sus fines, los científicos no se preguntan por los principios -los fundamentos- de su quehacer, al punto de llegar a una situación paradójica: sustentar que los hechos son la única evidencia válida y olvidar que la ciencia misma es un hecho que, por cierto, no es dado, sino producido, es un producto del espíritu.

Postular la necesidad de una medicina social implica, entonces, caer en el laberinto oscuro de pedirle a una ciencia, que ha olvidado que es un producto humano, una creación del espíritu, que explique la producción de lo humano, la creación del espíritu. Para salir de este sin sentido habrá entonces que preguntarse por los factores que lo expliquen.

Husserl considera que este naturalismo de los científicos es producto del olvido de lo que los clásicos griegos habían enseñado: "el mundo circundante histórico de los griegos no es el mundo objetivo en sentido nuestro, sino la "representación del mundo" de los griegos, esto es, su concepción subjetiva del mundo, con todas las realidades para ellos vigentes de este mundo, p. ej., los dioses, los demonios, etc." (Husserl, 1935, p. 139).

Para salir del laberinto es preciso reconocer que la ciencia moderna no es más que una de las posibles representaciones del mundo, y, si ello es así, se hace necesario 
respetar y esforzarse por entender esas otras representaciones del mundo. El conocimiento es, pues, un asunto en discusión.

En lo que sigue me ocuparé de tres momentos claves en el abordaje de esta problemática por la teoría crítica de la sociedad: G. Lukács, T. Adorno y M. Horkheimer y, finalmente, J. Habermas, en su Teoría de la acción comunicativa. Me interesa mostrar que la solución del problema planteado y, en consecuencia, un posible tratamiento de la crisis de la razón, implican un giro epistemológico que va de la filosofía de la conciencia hacia la filosofía del lenguaje.

\section{RACIONALIZACIÓN Y COSIFICACIÓN}

El húngaro Georg Lukács (1886-1971) no solo fue filósofo, sociólogo y estudioso de la estética, sino también militante del Partido Comunista, Comisario de Educación y Cultura de la República Soviética Húngara (1919), Ministro de Cultura de la Revolución Húngara de 1956, docente de la Universidad de Budapest y miembro de la Academia de Ciencias de Hungría; también sufrió los rigores del exilio en Austria, Alemania, Unión Soviética y Rumania. Estos pocos datos biográficos para indicar que la obra intelectual de Lukács estuvo estrechamente vinculada con la actividad práctico-política y con una capacidad crítica suficiente para juzgar permanentemente sus elaboraciones teóricas, sus acciones prácticas y las relaciones entre ellas, al punto que buena parte de la crítica de la obra de la que me ocuparé a continuación proviene precisamente de un prólogo redactado por el mismo autor 45 años después de la publicación original.

Georg Lukács redactó Historia y consciencia de clase en 1922, cuando las revoluciones proletarias en Europa oriental, surgiadas al calor de la revolución rusa, habían sido derrotadas, pero, no obstante, se respiraba en la intelectualidad europea del momento los aires de la caída inminente de la sociedad burguesa: "Se basaba en la fe, por entonces aún muy viva, en que la gran oleada revolucionaria que en poquísimo tiempo iba a levantar al mundo entero al socialismo, o, por lo menos, Europa sin excepción, no había quedado en modo alguno detenida por la derrotas de Finlandia, Hungría y Baviera” (Lukács, 1985: vol. 1, p. 16).

Historia y consciencia de clase recoge algunos artículos previamente publicados por el autor y dos ensayos inéditos, uno de los cuales ocupará nuestra atención: $L a$ cosificación y la conciencia del proletariado. Allí Lukács comprende la evolución 
social como la historia de las formas de objetividad - de objetivación de la razón- y sus correspondientes formas de subjetividad. Por forma de objetividad entiende una forma de existencia o de pensamiento que caracteriza la totalidad de un determinado nivel evolutivo de la sociedad, "que influye decisivamento en todas las manifestaciones de la vida" (Lukács, p. 9).

Para determinar la forma específica de objetividad de la sociedad burguesa, Lukács retoma a Marx, por considerar que la expone en sus obras maduras: la mercancía; pero no se adentra en los aspectos económicos (valor de uso y valor), sino en su carácter fetichista, que renombrará como cosificación y que hará extensivo al conjunto de la vida social, es decir, como la forma de subjetividad correspondiente a la mercancía en tanto forma de objetividad burguesa.

Recordemos entonces a Marx y su análisis del fetichismo de la mercancía en El Capital:

El carácter misterioso de la forma mercancía estriba, por tanto, pura y simplemente, en que proyecta ante los hombres el carácter social del trabajo de éstos como si fuese un carácter material de los propios productos de su trabajo, un don natural social de estos objetos y como si, por tanto, la relación social que media entre los productores y el trabajo colectivo de la sociedad fuese una relación social establecida entre los mismos objetos, al margen de sus productores [...] las relaciones sociales que se establecen entre sus trabajos privados aparecen como lo que son; es decir, no como relaciones directamente sociales de las personas en sus trabajos, sino como relaciones materiales entre personas y relaciones sociales entre cosas (1977: Tomo I, p. 37-38).

Lukács señala que, para Marx, la forma mercancía no solo es el elemento fundamental para la comprensión de la economía capitalista, sino que constituye la forma que estructura el conjunto de la vida socio-cultural y subjetiva de la sociedad burguesa: las relaciones sociales, con la naturaleza externa y con la naturaleza interna quedan asimiladas a relaciones entre cosas; en términos habermasianos: se produce una confusión categorial en la que estos tres aspectos quedan todos asimilados a cosas perceptibles y manipulables, se experimentan y se piensan como relaciones entre cosas. Planteado así el problema, en la sociedad burguesa el conjunto de las manifestaciones de la vida socio-cultural termina asumiendo este carácter cosificado.

El secreto de este proceso de cosificación reside, pues, en la misma forma de producción de mercancías y, como parte de ella, en que la fuerza de trabajo es 
convertida en una mercancía más, es decir, el trabajador es asimilado a un objeto de cambio más, se cosifica, entra a ser un medio más en el proceso de producción, se convierte en objeto de cálculo, de racionalización, concepción que incluso es asumida por el trabajador mismo.

De esta forma, Lukács puede señalar la complementariedad entre cosificación y racionalización: los procesos de racionalización descritos por Weber para la economía y la política, en otros términos, la introducción de la acción racional con arreglo a fines en estos dos ámbitos de la vida social, son complementarios con los fenómenos de cosificación; los seres humanos se convierten en medios, en tanto que en desarrollo del proceso económico se despersonalizan, rompen sus nexos comunitarios marcados por valores culturales y normas que legitiman sus relaciones sociales, y sus relaciones quedan reducidas a simples transacciones realizadas por medio del valor de cambio generalizado, del dinero.

Conforme con su planteamiento, según el cual esta forma de subjetividad se extiende a todas las manifestaciones de la vida, Lukács considera que también cobija al conocimiento, a la ciencia, de la cual Kant resulta ser la expresión por excelencia de esta estructura cosificada. Allí donde el filósofo alemán se pregunta por la posibilidad de realizar en la metafísica el llamado giro copernicano, encuentra Lukács la evidencia de dicha conciencia cosificada.

Asíformuló Kant el problema: "Hasta nuestros días se ha admitido que todos nuestros conocimientos deben regularse por los objetos [...]. Ensáyese, pues, aún a ver si no tendríamos mejor éxito en los problemas de la Metafísica, aceptando que los objetos sean los que deban reglarse por nuestros conocimientos"1 (Kant, 1984, p. 90). Lukács encuentra aquí que el filósofo alemán recoge y explicita claramente el camino racionalista trazado por Vico, Descartes, Hobbes, Spinoza y Leibniz, de tal manera que, al expresar que los objetos se rigen por nuestro conocimiento, está mostrando que el conocimiento no es algo dado, sino producido por los seres humanos.

Aunque Lukács manifiesta su acuerdo con este planteamiento, encuentra varias razones para sustentar su carácter cosificado. En primer lugar, en tanto que Kant

1 La traducción que ofrece el filósofo húngaro es esta: "Se supuso hasta ahora que todo nuestro conocimiento tiene que regirse por los objetos... Inténtese ahora ver si no saldremos mejor adelante con las tareas de la metafísica suponiendo que los objetos tienen que regirse por nuestro conocimiento" (Lukács, 1985: vol. II, p. 41). 
no se pregunta cómo llegó a ser que los humanos encontraran que la razón solo descubre en la naturaleza lo que previamente ha puesto en ella, no hacer esta pregunta equivale para Lukács asumir este fenómeno como algo dado (obvio) y no como algo producido históricamente. La presunta ausencia de una explicación histórico-genética del conocimiento, que complemente la racional es, para el filósofo húngaro, la evidencia de que el producto (conocimiento) domina al productor (filósofo, científico).

En segundo lugar, el argumento kantiano según el cual la universalidad de las leyes naturales solo es posible determinarla por medio de la Razón, y que la indagación empírica está orientada a establecer la verdad o falsedad de tales leyes previamente pensadas ${ }^{2}$, es visto por Lukács como otro rasgo de la cosificación de la conciencia, en tanto que de esta manera se asume el método científico como el único válido para estudiar todas las formas del ser.

Así lo expresa Habermas: "La teoría kantiana del conocimiento despedaza sin misericordia las ilusiones metafísicas del pasado, entierra las pretensiones dogmáticas de la razón objetiva, pero solo lo hace, piensa Lukács, para justificar el cientificismo, es decir, la suposición otra vez dogmática de que "la forma de conocimiento formalista-racional es 'para nosotros' la única forma posible de aprehender la realidad" (Habermas, 1999: vol. I, p. 460).

El tercer rasgo de la ciencia como conciencia cosificada se relaciona con su carácter formalista. En tanto que la ciencia moderna otorga prioridad lógica al concepto (abstracto, formal) sobre la intuición (concreta, material), Lukács ve en ello una subestimación de la materialidad del mundo, del contenido de las proposiciones: si las leyes pueden formularse por medio del entendimiento, prescindiendo de las particularidades que ofrece la materia (que califica como irracional), entonces el contenido deviene puramente accidental a la forma, no se presenta una unidad orgánica entre forma y contenido.

La universalidad kantiana, entonces, y en cuarto lugar, no es tal, puesto que al postularse en su abstracta racionalidad (formalidad) deja de lado lo material (el contenido), y para Lukács la auténtica universalidad es aquella que comprende la totalidad: lo racional y lo irracional, la forma y el contenido, lo abstracto y lo concreto.

2 Una presentación de la explicación kantiana de la ciencia puede verse en: Rojas, 2003. 
Lukács explora entonces otra de las obras de Kant, Crítica de la razón práctica, para ver si allí encuentra la unidad de contrarios; un indicio en este sentido lo advierte en el procedimiento de universalización de las máximas para hallar las leyes de la moralidad: "Es verdad que intenta hallar en el principio de no contradicción un principio a la vez formal determinador de contenidos, negativamente al menos"3 (Lukács, vol. II, p. 57).

No obstante, allí no es posible encontrar el buscado principio unitario, en tanto que Kant distingue claramente las leyes de la libertad (de la moral) de las leyes de la causalidad (empírica). Las primeras: incondicionadas y pensadas por seres racionales, en tanto noúmenos; las segundas: condicionadas y experimentadas por objetos inmersos en la cadena causal de la naturaleza, objetos que nos son dados como fenómenos ${ }^{4}$. Este mutuo extrañamiento entre libertad y necesidad es considerado otro de los rasgos de la cosificación de la conciencia en la sociedad burguesa.

Tanto la ética kantiana como su comprensión del conocimiento científico son, para el filósofo húngaro, abstractas, formalistas, enajenada la una del otro y, en consecuencia, expresiones de la cosificación de la conciencia.

El filósofo húngaro retoma la crítica hegeliana a Kant en el sentido de la separación que establece entre sujeto y objeto y, también, su planteamiento de la reconciliación, para luego retomar la crítica de Marx a Hegel: la filosofía ha de negarse, tornarse real, concreta, para demostrar la verdad de sus afirmaciones.

Todo intento de superar la dualidad dialécticamente en el pensamiento exento de toda relación concreta con el ser, en la pura lógica -como, a pesar de todas las tendencias contrarias, lo fue el intento de Hegel-está condenado al fracaso. Pues toda lógica pura es platónica, es pensamiento desprendido del ser y cristalizado en esta separación. Sólo en la medida en que el pensamiento aparezca como forma de la realidad, como momento del proceso total, puede superar dialécticamente su propia rigidez y tomar un carácter de devenir [...]. Sólo cuando el hombre consigue percibir el presente como devenir y reconoce en él las tendencias con cuya contraposición dialéctica él mismo es capaz de

3 El planteamiento kantiano es este: "no debo obrar nunca más que de modo que pueda querer que mi máxima deba convertirse en ley universal" (Kant, 1986, p. 27).

4 Una aplicación de la ética kantiana a la comprensión y superación de la violencia en Colombia puede verse en: Rojas, 2007. 
producir el futuro, sólo entonces el presente, el presente como devenir, se convierte en el presente suyo. Sólo el que está llamado a producir el futuro y quiere hacerlo puede ver la verdad concreta del presente" (Luckács, Vol. II, pp. 152-153).

Esta idea de negación de la filosofía como forma de determinación de su verdad es la que está en la base de la práctica política Lukács. Así, también, el principio del devenir lo lleva a hacer de los resultados de su práctica objeto de reflexión, esta es la tarea que realiza en el prólogo a una nueva edición de su obra 45 años después, al cual hice referencia al comienzo de este apartado.

En este prólogo, redactado en 1967, Lukács define a Historia y consciencia de clase como la obra en que culmina su proceso de formación juvenil, y ofrece algunos elementos de juicio sobre la situación política de cuando fue escrita, de las valoraciones que hizo en su momento y de las discusiones con los representantes de otras tendencias del marxismo, para, y es lo que interesa aquí, mostrar las limitaciones teóricas de su obra y las consecuencias prácticas que acarrean.

Sibien es cierto que el filósofo húngaro considera que la comprensión de la totalidad, como fundamento de una comprensión dialéctica de la historia, sigue siendo válida, expresa que en Historia y consciencia de clase, antes que realizar la síntesis de contrarios, lo que hizo fue confundirlos, poner el uno en el lugar del otro, fenómeno que llama "pluscuamhegelización de Hegel". La confusión es esta: considerar que se ponía a Hegel "con los pies en la tierra" si en el lugar del razonamiento lógicofilosófico se ubicaba el proceso histórico-social:

Cierto que en el pensamiento de Hegel la génesis del sujeto-objeto idéntico es de naturaleza lógico-filosófica, pues la consecución del supremo estadio del Espíritu en la filosofía, con la retrocapción de la extrañación o alienación, con la vuelta de la autoconsciencia a sí misma, es lo que realiza el sujeto-objeto idéntico. En cambio, en Historia y consciencia de clase este proceso se supone histórico-social, y culmina en el hecho de que el proletariado, convirtiéndose en sujeto-objeto idéntico de la historia, realiza dicho estadio en su consciencia de clase. Con eso parece que se haya puesto efectivamente a Hegel "con los pies en el suelo" (Luckács, Vol. I, p. 27).

Poner el proceso histórico-social en el lugar del argumento lógico-filosófico es lo que lleva a Lukács y a los intelectuales marxistas de su momento a considerar que el 
proletariado es la clase social que, con base en el conocimiento científico de la realidad, está llamada a liderar el proceso de emancipación humana, es decir, a materializar el postulado filosófico, a negar la filosofía para mostrar su verdad.

Cuarenta y cinco años más tarde, el exilio, dos guerras mundiales, la materialización del socialismo en una tercera parte del planeta, la reflexión sobre sus propias prácticas y sus elaboraciones teóricas, llevan a que Lukács pueda establecer la falsedad de su argumento inicial:

Pero ¿es realmente el sujeto-objeto idéntico algo más que una construcción puramente metafísica? ¿Se produce realmente un sujeto-objeto idéntico en un autoconocimiento, por perfecto y adecuado que éste sea, y aunque se base en un conocimiento adecuado del mundo social, es decir, aunque ese autoconocimiento se dé en la más consumada autoconsciencia? Basta con formular la pregunta de un modo preciso para verse obligado a responderla negativamente. Pues por mucho que el contenido del conocimiento pueda referirse al sujeto conocedor, el acto de conocimiento no pierde por ello su carácter alienado (Luckács, Vol. I, p. 27).

El filósofo húngaro encuentra que el problema deriva de una comprensión descuidada de los conceptos básicos: objetificación (en la edición de 1923: objetivación) es el producto inevitable de la acción social humana: todas nuestras acciones, en tanto que se materializan (que se hacen realidad), conducen a la creación de objetos; extrañación implica que los objetos producidos no están puestos al servicio de su productor, sino en su contra: "el fenómeno de la cosificación, muy emparentado con el de extrañación, pero ni social ni conceptualmente idéntico con él, se utilizó en la obra como sinónimo del otro" (Luckács, Vol. I, p. 29).

Bien es cierto que podríamos continuar realizando precisiones conceptuales en el documento objeto de estudio, pero para los propósitos del presente escrito basta con lo dicho: que la confusión entre la necesaria objetivación de las acciones humanas se analizó como sinónimo de cosificación, es decir, de dominación de los seres humanos por sus productos, y que, sobre estas bases, se consideró que si la clase obrera tomaba conciencia de esta alienación de sus obras bastaría para producir la emancipación humana.

Lukács también encuentra equívocos en relación con la práctica, los que atribuye al mesianismo utópico de la época: 
Yo tenía presente [...] que, a diferencia de la consciencia trade-unionista, de nacimiento espontáneo, la consciencia socialista tiene que llevarse a los trabajadores "desde afuera", "es decir, desde fuera de la lucha económica, desde fuera de las relaciones entre trabajadores y empresarios" [...] La mutación de la conciencia "atribuída" en práctica revolucionaria resulta en Historia y consciencia de clase, si se considera objetivamente el texto, un verdadero milagro (Luckács, Vol. I., pp. 22-23).

Así, entonces, el filósofo húngaro reconoce imprecisiones conceptuales entre objetivación y cosificación (en este caso particular, del conocimiento) y, por otro lado, que no logra explicar satisfactoriamente la relación entre práctica (en este caso revolucionaria) y conocimiento, con lo cual el problema de la alienación y la posible emancipación humana quedan teóricamente sin resolver, posiblemente, por que, a juicio de Lukács, como lo había advertido Hegel: "Su sano sentido de la realidad hizo que dejara esta búsqueda en mera postulación [...]. Hegel no muestra nunca concretamente, dentro de su sistema, cómo podría cumplirse lo postulado" (Luckács, Vol. I, p. 27).

\section{Mito E ILUSTRACión}

El filósofo y sociólogo alemán Max Horkheimer (1895-1973) prestó servicio militar durante la Primera Guerra Mundial, y luego de ella estudió filosofía y psicología; fue docente de la Universidad de Frankfurt y director del Insitituto de Investigación Social de la misma universidad; con la llegada del fascismo al poder, en 1930, le fue revocada su condición de profesor y cerrado el Instituto, ante lo cual se exilió, primero en Suiza y luego en Estados Unidos. Al concluir la guerra regresó a Alemania y se desempeñó como rector y docente de la citada Universidad de Frankfurt.

Theodor Adorno (1903-1969), filósofo y sociólogo alemán, fue además músico, compositor y estudioso de la estética; integrante del Insitituto de Investigación Social de la Universidad de Frankfurt, vivió en el exilio, primero en Inglaterra (Oxford) y luego en Estados Unidos; regresó a Alemania en 1949 y se desempeñó como director del referido Instituto y docente de la Universidad de Frankfurt.

A diferencia de la fe [...], en que la gran oleada revolucionaria que en poquísimo tiempo iba a levantar al mundo entero al socialismo, expresada en 1922 por Lukács en medio de las derrotas de las revoluciones obreras y tras la Primera Guerra Mundial, Horkheimer y Adorno ofrecen en 1944 un lúgubre panorama que perdura incluso 25 años después (1969): "Lo que nos habíamos propuesto era 
nada menos que comprender por qué la humanidad, en lugar de entrar en un estado verdaderamente humano, se hunde en un nuevo género de barbarie" (Horkheimer y Adorno, 1994, p. 51).

Este era, precisamente, el objetivo inicial de su Dialéctica de la Ilustración, redactada entre 1942 y 1944, en medio de la Segunda Guerra Mundial, y cuando se encontraban en el exilio en Los Ángeles, California. La obra fue publicada en 1947, y una segunda edición vio la luz en 1969 sin que, a juicio de los autores, esta tendencia hacia la barbarie se hubiera detenido, sino tan solo quebrado: "Ella amenaza con imponerse y realizarse a través de dictaduras y guerras" (Horkheimer y Adorno, p. 50).

Mientras que para Husserl era posible enfrentar la crisis de la humanidad europea haciendo uso de la epojé y la reducción fenomenológica ${ }^{5}$, a la vez que para Luckács lo era con la conciencia y la praxis revolucionarias, para Horkhaimer y Adorno solo queda la invitación a mantener una actitud vigilante del momento negativo de la Ilustración, del germen regresivo que lleva en sí misma y que es posible documentar tanto en el concepto mismo como en las formaciones históricas y en las instituciones sociales en que ha tomado cuerpo dicho concepto.

Horkheimer y Adorno no buscan explicar este fenómeno regresivo en sus manifestaciones más recientes (en las prácticas fascistas), sino en sus orígenes mismos: en el mito. Los autores parten de considerar el mito y la Ilustración como opuestos, pero su argumentación no se orienta a mostrar su unidad, sino a documentar su identidad: "el mito es ya Ilustración; la Ilustración recae en mitología" (Horkheimer y Adorno, p. 56).

Dialéctica de la Ilustración lleva por subtítulo Fragmentos filosóficos; en cada uno de ellos los autores pretenden sustentar su tesis de la identidad entre mito e Ilustración, bajo un común denominador: la idea según la cual 'Poder y conocimiento son sinónimos" (Horkheimer y Adorno, p. 60). Veamos entonces algunos de dichos fragmentos.

Los filósofos retoman un aparte de la obra de Bacon, el "padre de la filosofía experimental", aldecir de Voltaire, para sustentar que las pretensiones de la Ilustración han sido: liberar a los seres humanos del miedo que les genera lo desconocido (los

5 Sobre Husserl y su método fenomenológico véase: Hoyos y Vargas, 1997; también, Hoyos, 2011. 
dioses y los demonios) y convertirlos en amos y señores tanto de la naturaleza como de otros seres humanos. En palabras de Bacon: 'La ciencia del hombre es la medida de su potencia, porque ignorar la causa es no poder producir el efecto. No se triunfa de la naturaleza sino obedeciéndola" (Bacon, 1984, p. 27).

Así, entonces, para Horkheimer y Adorno, Ilustración significa desencantamiento del mundo y dominación. Este desencantamiento impulsado por la moderna ciencia experimental ha seguido un vertiginoso proceso en el que los logros tempranos de dicha ciencia, de la filosofía e incluso del lenguaje cotidiano son comprendidos ahora como rezagos en forma secularizada de los antiguos dioses y demonios, de los antiguos temores: el nominalismo baconiano, los conceptos de sustancia y cualidad, actividad y pasión, ser y existencia, verdad e incluso el de causa son algunos de los ahora considerados ídolos del teatro, residuos mitológicos, expresión de fuerzas superiores o inmanentes, en una palabra, animismo.

El concepto de verdad, por ejemplo, en tanto que simple placer que produce conocer, es considerado lascivia estéril, puesto que no se muestra como procedimiento eficaz. El concepto de causa, por su parte, es visto como la secularización del principio de la creación divina. La moderna ciencia experimental, en su manifestación positivista, puede deshacerse no solo de estos conceptos, sino del concepto en general, del pensar teórico, puesto que con el solo método, devenido en técnica (fórmula, regla y probabilidad), le basta para encontrar los hechos o los datos que permiten dominar la naturaleza, hacer uso de ella para la producción mercantil o, también, para disponer del trabajo ajeno: la eficacia, la utilidad y el control son los criterios que se imponen para determinar eléxito o el fracaso del quehacer científico.

Si bien es cierto que la ciencia positivista puede renunciar a los conceptos, ello no implica que haga lo mismo con la abstracción; lo heterogéneo, efectivamente, puede reducirse a lo equivalente, a lo abstracto que permite el intercambio: a la unidad y su integración en el sistema; al número que reduce las cualidades, que es conmutable y distributivo (no solo en el mercado, sino también en la justicia); al lenguaje lógico que depura al lenguaje cotidiano de las restos mitológicos. La ciencia en su versión positivista, esta ciencia de hechos, ha llevado hasta sus últimas consecuencias la pretensión de la Ilustración: el desencantamiento del mundo y el dominio, por eso puede señalar sin ambajes que saber es poder.

Pero es aquídonde, precisamente, Horkhemer y Adorno encuentran que la Ilustración recae en mitología: al establecerse la ciencia positivista como la única forma de 
conocer, deviene en dogma que rechaza todo lo exterior a ella, le atemoriza todo aquello que pretende escapar de sus rígidos cánones; los dioses y los demonios han regresado bajo la forma de temor a todo aquello que no sea lo dado, lo eficaz, lo útil, lo controlable: "La Ilustración es el temor mítico hecho radical. La pura inmanencia del positivismo, su último producto, no es más que un tabú en cierto modo universal" (Horkeimer y Adorno, p. 70).

Pero nuestros autores han postulado también: el mito es ya Ilustración, es decir, dominio y desencantamiento; veamos entonces cómo documentan esta afirmación con la mitología griega, en particular La odisea, la narración del proceso en el que Ulises busca afirmar su propio destino, construir su identidad, emanciparse, y para ello se enfrenta a los poderes de la naturaleza-externa e interna-, que es simbolizada en el canto de las sirenas. Este es el pasaje del que se ocupan los autores, son las advertencias de la diosa Cirse:

Oye ahora lo que voy a decir y un dios en persona te lo recordará más tarde. Llegarás primero a las sirenas, que encantan a cuantos hombres van a su encuentro. Aquel que imprudentemente se acera a ellas y oye su voz, ya no vuelve a ver a su esposa ni a sus hijos pequeñuelos rodeándole, llenos de júbilo, cando torna a sus hogares; sino que le hechizan las sirenas con el sonoro canto, sentadas en una pradera y teniendo a su alrededor enorme montón de huesos de hombres putrefactos cuya piel se va consumiendo. Pasa de largo y tapa las orejas de tus compañeros con cera blanda, previamente adelgazada, a fin de que ninguno las oiga; mas si tú deseares oirlas, haz que te aten en la velera embarcación de pies y manos, derecho y arrimado a la parte inferior del mástil, y que las sogas se ligen al mismo tiempo; y así podrás deleitarte escuchando a las sirenas. Y caso de que supliques o mandes a los compañeros que te suelten, átente con más lazos todavía (Homero, 1974, p. 232).

En este pasaje, considerado por Horkheimer y Adorno una temprana expresión de la Ilustración burguesa, encuentran lo regresivo del dominio humano sobre la naturaleza: para enfrentar los peligros que le han sido comunicados, los humanos toman una de las opciones igualmente represivas: hacer oidos sordos a los llamados de lo desconocido o apreciar su belleza, pero a condición de atarse a sí mismo.

Ulises (el señor terrateniente) toma esta segunda opción y, de manera proporcional a la embriaguez que le producen los bellos cantos de las sirenas, es atado con más fuerza por sus compañeros (los trabajadores), que, sin escuchar la belleza de lo 
desconocido, se mantienen ocupados remando hasta alcanzar el destino previamente determinado.

La similitud o identidad con la moderna y desencantada sociedad salta a la vista: Ulises, así como el burgués, aunque dispone del poder sobre el trabajo de otros que le sirven, es impotente para gozar plenamente la belleza que la naturaleza le ofrece, tanto como para participar del proceso productivo (del trabajo); los compañeros de Ulises, al igual que los obreros modernos, se mantienen ocupados en sus labores, son los productores de las obras humanas, pero no pueden disfrutar de la belleza que crean, ni siquiera pueden imaginarla.

Horkheimer y Adorno encuentran aquí cómo ciencia, trabajo y arte se separan en tanto esferas de la acción humana enajenadas unas de otras y que conducen a la miseria humana, lo cual interpretan no como una desviación del progreso humano, sino como su consecuencia inevitable, el progreso trae consigo la regresión: "La fantasía se atrofia [...] la adaptación al poder del progreso implica el progreso del poder [...] La maldición del progreso imparable es la imparable regresión" (Horkheimer y Adorno, 1994, p. 88).

Para los autores, los poderes colectivos que se expresan en el mito y que se actualizan en el rito, en el acto sacrificial, y que garantizan la cohesión e integración social, se entronizan en el individuo ahora en la forma de un poder autoimpuesto, un poder que sacrifica lo valioso de la autoconservación-la vida-al imperio de la racionalidad instrumental: el espíritu no escapa a este progreso y se convierte en aparato del dominio y autodominio, el arte deviene en mero entretenimiento, en cultura de masas.

De esta manera los autores arrancan a la modernidad uno de los elementos que se consideraron su patrimonio: la Ilustración; esta es ahora entendida como un proceso global de lucha entre los poderes colectivos (alejamiento de los orígenes, del mito) y el de individuación (emancipación, liberación), como una sucesión de etapas en la que el mito se torna Ilustración, y esta, fatalmente, deviene mitología. Aceptando esta comprensión, la crítica viene ahora por cuenta de Habermas, puesto que si:

el proceso de Ilustración, desde sus mismos comienzos, se debe al impulso de una autoconservación que mutila a la razón porque sólo se sirve de ésta en la forma de una dominación "racional con arreglo a fines" de la naturaleza y de los impulsos, es decir, sólo se sirve de ésta en la forma de razón instrumental [...] con ello todavía no se ha mostrado que la razón, hasta en sus más recientes 
productos, como son la ciencia moderna, la ideas morales jurídicas universalistas y el arte autónomo, permanezca sometida al dictado de la racionalidad con arreglo a fines (1989, p. 140).

Para Horkheimer y Adorno, el positivismo lógico es la comprensión más acabada de las ciencias modernas y, en él, las pretensiones teóricas son sustituidas por la utilidad técnica. $\mathrm{Si}$, además, se considera que ante el avance de las ciencias, tanto la religión como la filosofía han perdido su capacidad para proporcionar fundamentos racionales a la moral y al derecho y, por otro lado, que la industria de la cultura suplanta con la imitación el esfuerzo creativo de búsqueda de la propia identidad, tendremos que en sus más recientes productos la Ilustración también deviene en racionalidad instrumental, es decir, que los momentos aislados de la razón "entran en regresión y se reducen a una racionalidad al servicio de una autoconservación que se ha vuelto salvaje" (Habermas, 1989, p. 142).

Habermas no comparte la crítica en estos términos, en tanto que, al asimilar de esta manera pretensiones de validez y pretensiones de poder, se desconoce que uno de los rasgos de la modernidad cultural es la separación de esferas de valor -ciencia, moral, derecho, arte- en las que la capacidad de crítica, antes que limitarse, se ve potenciada: la crítica y fundamentación en cada una de dichas esferas asume su propia lógica, se conforma una cultura de expertos para la cual resulta problemático tratar problemas de verdad, de justicia o de gusto, ateniéndose solo a pretensiones de poder y dejar de lado la capacidad de tomar postura con un "sî" o con un "no" ante los asuntos objeto de discusión; así, advierte el autor, el riesgo es que se presente ahora el alejamiento de estos expertos con respecto a la vida cotidiana.

Para Habermas, la lectura de Horkheimer y Adorno resulta unilateral, por una razón más: se limita a mostrar la instrumentalización, dejando de lado las objetivaciones que, junto con ella, ha logrado la razón: la dinámica teorética y la autorreflexión, que empujan permanentemente a la ciencia por encima del saber técnicamente utilizable; las instituciones de los Estados constitucionales modernos; los procesos de formación democrática de la voluntad y los patrones individualistas de formación de la identidad, $y$, finalmente, la fuerza explosiva de una subjetividad descentrada que encuentra en el arte de vanguardia la crítica de arte y las experiencias innovadoras de autorrealización personal y grupal, sus expresiones instructivas.

Si hasta aquí ha sido analizada la relación entre mito e Ilustración, en tanto que fuerzas contrarias, Habermas se ocupa de mostrar su carácter antitético: el mito 
mantiene unidos todos los fenómenos en una red de correspondencias y semejanzas en lo que, para el pensamiento ilustrado, resulta ser una confusión categorial entre naturaleza y cultura; junto con ello, el mito no es susceptible de crítica, en tanto que, como factor de cohesión social, cuestionarlo implica poner en peligro el orden social constituido por él: "Las tradiciones míticas no pueden revisarse sin poner en peligro el orden de las cosas y la identidad de la tribu, que se funda en ese orden. Categorías de validez como "verdadero" y "falso", "bueno" y "malo" forman una aleación con conceptos empíricos como trueque, causalidad, salud, sustancia y capacidad" (Habermas, 1989, p. 144).

El pensamiento ilustrado, por el contrario, separa lo que en el mito se encuentra unido: naturaleza y cultura, verdad y justicia, concepto y realidad, mundo e imagen del mundo; mundo objetivo y mundo social; estos últimos del mundo subjetivo; ciencia y religión; en fin, se diferencian esferas de valor que asumen cada una su propia lógica, es decir, se diferencian pretensiones de validez: verdad, rectitud normativa y autenticidad.

A juicio de Habermas, solo después de que se han diferenciado estas esferas de valor con sus respectivas pretensiones de validez, se presenta la posibilidad de distinguir estas últimas de las pretensiones de poder; es el momento en el que aparece la crítica ideológica: esta busca determinar cómo tras las pretensiones de validez se ocultan pretensiones de poder. En este momento la Ilustración se torna por primera vez reflexiva, es decir, se vuelve contra sus propios productos: somete a crítica las teorías.

La crítica ideológica, la primera reflexivización de la Ilustración, es obra de Marx; Horkheimer y Adorno, por su parte, hacen que la Ilustración se torne por segunda vez reflexiva: someten a crítica la crítica ideológica, se preguntan por sus fundamentos, es decir, por la razón. Para Marx, el trabajo científico consistía en develar cómo tras los ideales burgueses se escondían intereses particulares, de clase, y para ello se atenía a una razón inscrita en la historia y sobre la cual no se cuestionaba.

Horkheimer y Adorno, por su parte, aunque mantienen su carácter crítico, señalan las limitaciones del fundamento de la crítica ideológica: la razón instrumental, efectivamente, se ha asimilado al poder y ha renunciado a su capacidad crítica, pero con ello se llega a una situación paradójica: "Mas esta [la razón] se ve en la precisión de describir la autodestrucción de la capacidad crítica en términos asaz paradójicos, porque en el instante en que efectúa tal descripción no tiene más remedio que seguir haciendo uso de la crítica que declara muerta" (Habermas, 1989, p. 149). 
Para Habermas, el camino seguido por Horkheimer y Adorno fue, ante la paradoja de continuar con la crítica cuando se han consumido las razones para ello, el de la negación determinada, con lo cual los autores se entregaron:

a un desbocado escepticismo frente a la razón, en lugar de ponderar las razones que permitían a su vez dudar de ese escepticismo [...] Permaneció prisionera de la idea purista de que en las relaciones internas entre génesis y validez se oculta un demonio que hay que exorcizar para que la teoría, purificada de toda adherencia empírica, pueda moverse en el terreno que le es propio [...] Sólo un habla que sea capaz de confesarse esto a sí misma, será capaz aún de romper el hechizo del pensamiento mítico sin verse privada de la luz de los potenciales semánticos que el mito también conserva. (Habermas, 1989, p. 162).

\section{LOS LÍMITES DE LA FILOSOFÍA DE LA CONCIENCIA Y LA NECESIDAD DE UN CAMBIO DE PARADIGMA}

Como hemos visto, Adorno, Horkheimer ni Lukács logran ofrecer una explicación satisfactoria de la crisis de la modernidad que se presenta en el siglo XX. Habermas explica este fenómeno como consecuencia de haberse mantenido los autores prisioneros de la estrategia conceptual propia de la filosofía de la conciencia, y agrega que, para superar este vacío, es necesario realizar un cambio de paradigma hacia la filosofía del lenguaje, del entendimiento intersubjetivo o de la comunicación. Veamos primero las limitaciones del modelo cuestionado y luego las características más generales del que se propone.

Para la filosofía de la conciencia, la subjetividad determina sus acciones a partir de sus propias estructuras (autonomía) y, a la vez, reconoce un proceso que se desarrolla con independencia de tal subjetividad. En esta distinción se entiende por objeto "todo lo que puede ser representado como siendo; y por 'sujeto', la capacidad de referirse en actitud objetivante a tales entidades en el mundo y la capacidad de adueñarse de los objetos, sea teórica o prácticamente" (Habermas, 1999: vol. I, p. 494).

El sujeto dispone de dos atributos: la representación y la acción; por medio de la primera aprehende los objetos como son; con la segunda, interviene en el mundo para producirlos como quiere que sean; estas dos capacidades se enlazan en tanto que el conocimiento (representación) está referido a la posibilidad de la intervención en el mundo (acción) y, a la vez, la acción para tener éxito requiere del conocimiento, de la aprehensión de la cadena causal en la que están inscritos los objetos. 
Ahora bien, Habermas muestra que esta comprensión del sujeto implica una transformación del concepto de autoconservación. Para los antiguos, todo ser llevaba inscrito en su ser un telos inmutable que aspiraba a realizar, esta era su naturaleza. En palabras de Aristóteles, para el caso de los asuntos humanos: "Y por naturaleza [uno] manda y [otro] obedece para la supervivencia. Quien con la inteligencia es capaz de prever está naturalmente destinado a ser amo, y quien tenga fuerza corporal para realizar [lo planeado por aquél] es, por naturaleza, esclavo; por eso hay un interés [mutuo] entre amo y esclavo" (Aristóteles, 2002, p. 37).

Por su parte, la comprensión moderna de la autoconservación reemplaza esta comprensión de la esencia inmutable por la del cambio: a la manera de la física newtoniana, que asume que todo cuerpo mantiene su estado de reposo o de movimiento rectilíneo mientras no se ejerzan otras fuerzas sobre él, para "la filosofía social burguesa y la economía burguesa, todo sujeto conserva socialmente su vida persiguiendo racionalmente su propio interés bien entendido" (Habermas, 1999: vol. I, p. 495).

Desde esta perspectiva, asegura Habermas, los dos atributos del espíritu representación y acción- quedan convertidos en medios para la consecución de un único fin: asegurar la existencia contingente, es decir, la razón subjetiva queda reducida a razón instrumental y, en consecuencia, las posibilidades de la solidaridad, es decir, de la presencia de lo universal en lo particular, se ven seriamente limitadas: la sociedad queda reducida a un agregado de individuos atomizados en el que cada cual busca su propia supervivencia.

Esta comprensión determina un comportamiento igualmente instrumental de la sociedad en su conjunto hacia la naturaleza externa, de unas clases hacia otras en la organización social y del individuo con respecto a su naturaleza interna; en todos los casos se asimila el ser de los entes a cosas y, en cuanto tal, se los utiliza como medios para la consecución de un único fin: la autoconservación.

Adorno, Horkheimer y Lukács reconocen los efectos de esta instrumentalización de la naturaleza externa e interna y de las relaciones sociales, pero no pueden explicar en qué consisten dichos efectos, y ello es así en tanto que desde el complejo conceptual de la filosofía de la conciencia es imposible comprender la instrumentalización desde la perspectiva de aquellos que han sido reducidos a la condición de objetos, no es posible: 
decir a esa naturaleza objetivada que es lo que con ello [el control] se le está inflingiendo. La razón instrumental es una razón "subjetiva" también en el sentido de que expresa las relaciones entre sujeto y objeto desde la perspectiva del sujeto cognoscente y agente, pero no desde la perspectiva del objeto percibido y manipulado. De ahíque no ofrezca ningún medio de explicar qué significa la instrumentalización de las relaciones sociales e intrapsíquicas, vista desde la perspectiva de la vida violentada y deformada (Habermas, 1999: vol. I, p. 497).

La filosofía del lenguaje resulta ser, en consecuencia, el modelo que posibilita la expresión y la explicación desde la perspectiva de la vida violentada y deformada, en tanto que substituye la racionalidad cognitivo-instrumental por la racionalidad comunicativa: en lugar de ocuparse de la explicación del conocimiento y del sojuzgamiento de la naturaleza objetivada, aborda la intersubjetividad del entendimiento posible tanto en las relaciones sociales como en terreno intrapsíquico.

Ahora bien, el recurso a la filosofía del lenguaje demanda, para hacer posible la expresión de la vida violentada y deformada, superar el modelo diádico de oración y estados de cosas por uno de carácter triádico: un hablante que se entiende con un oyente sobre objetos y estados de cosas. Esta ampliación del uso del lenguaje -del meramente expositivo al comprensivo entre sujetos- permite además poner de presente otras dos funciones del lenguaje: "Bühler distingue tres funciones en el uso del signo: la función cognitiva de exposición de un estado de cosas, la función expresiva de mostración de vivencias del hablante y la función apelativa de exigencias dirigidas a los destinatarios" (Habermas, 1999: vol. I, p. 354).

La acción comunicativa, a diferencia de la acción teleológica, posibilita ampliar la relación sujeto-objeto con las relaciones entre: sujetos que se entienden sobre algo en el mundo (para conocerlo o para producirlo), individuos que pueden hacer comprensibles sus vivencias subjetivas y sujetos que establecen relaciones sociales: "En este proceso de entendimiento los sujetos, al actuar comunicativamente, se mueven en el medio del lenguaje natural, se sirven de interpretaciones transmitidas culturalmente y hacen referencia simultáneamente a algo en $e l$ mundo objetivo, en $e l$ mundo social que comparten y cada uno a algo en su propio mundo subjetivo" (Habermas, 1999: vol. I, pp. 499-500).

Este cambio de un sujeto cognoscente y agente por el de sujetos capaces de lenguaje y acción implica, en consecuencia, un cambio en el concepto de autoconservación: 
la búsqueda de la supervivencia individual en un medio hostil es reemplazada por la cooperación social, tanto para reproducir la vida material como la vida espiritual o simbólica.

El espectro de la racionalidad se amplía para cubrir tanto la acción racional con arreglo a fines (reproducción de la vida material) como la acción comunicativa; esta última posibilita que los individuos, en tanto sujetos capaces de lenguaje y de acción, produzcan y reproduzcan un mundo de la vida que, simbólicamente estructurado, constituye su espacio tanto de individuación como de socialización:

Así, la razón comunicativa no se limita a dar por supuesta la consistencia de un sujeto o de un sistema, sino que participa en la estructuración de aquello que se ha de conservar. La perspectiva utópica de reconciliación y libertad está basada en las condiciones mismas de la socialización comunicativa de los individuos, está ya inserta en el mecanismo linguiístico de reproducción de la especie (Habermas, 1999: vol. I, p. 499-500).

$\mathrm{Si}$, conforme con lo hasta aquí expuesto, advertimos en términos generales la necesidad del cambio de paradigma, ampliemos entonces el concepto de racionalidad comunicativa.

\section{ACERCAMIENTO PRELIMINAR AL CONCEPTO DE RACIONALIDAD COMUNICATIVA}

El sociólogo y filósofo alemán Jürgen Habermas nació en el período de entre guerras (1929) e inició sus estudios universitarios cinco años depués de concluir la Segunda Guerra Mundial (1949); entre sus maestros se encuentran, precisamente, Horkheimer y Adorno, quienes recién retornaban del exilio; de este último, fue asistente de investigación en el Instituto de Investigación Social de Frankfurt.

Habermas ha participado activamente en las discusiones sobre el sentido de la sociedad y el Estado alemán de posguerra, tras la barbarie (tanto de la República Federal como luego de la reunificación), a la vez que se ha ocupado de los límites de la tradición sociológica y filosófica de la que forma parte. De su vasta producción, bien pueden destacarse, con respecto a la primera temática: Identidades nacionales y postnacionales y Ciudadanía e identidad nacional; con respecto a la segunda: La reconstrucción del materialismo hitórico, Ciencia y técnica como ideología y Conocimiento e interés. 
En Teoría de la acción comunicativa, Habermas logra establecer su propia perspectiva teórica, y en Facticidad y validez hace uso de ella para la comprensión del derecho y el Estado. En lo que sigue, y para los propósitos señalados, me apoyaré en la primera de estas obras.

En la introducción a su Teoría de la acción comunicativa, Habermas expone que, desde sus inicios, el tema fundamental de la Filosofía ha sido la razón, y se pregunta: "¿cómo puede entonces la Sociología tener competencias en lo tocante a la problemática de la racionalidad?' (Habermas, 1999: vol. I, p. 16). Para responder el interrogante, el autor indica que ciencias sociales, tales como la Economía o la Ciencia Política, se vieron en la necesidad de limitar sus objetos de estudio a elementos parciales de la vida social, desligándolos de aspectos normativos, es decir, de los nexos con los asuntos práctico-morales y de legitimación que proporcionaba el derecho natural racional. En otros términos, en su proceso de especialización estas dos ciencias asumieron la economía y la política como dos subsistemas a los que estudian en sus dimensiones funcionales y, con ello, reducen la racionalidad a problemas de elección o de equilibrio que solo requieren ser abordados de manera empírica o descriptiva sin interrogar por los fundamentos que los legitiman.

Caso contrario sucede con la Antropología Cultural y con la Sociología, puesto que estas dos disciplinas demandan ocuparse del estudio de la sociedad global en tanto que los procesos de reproducción cultural, de integración socialy de socialización tienen lugar en mundos socioculturales de la vida estructurados simbólicamente, cargados de sentido y cuya comprensión y explicación plena no es posible si se los reduce a sistemas funcionales que conservan sus límites en un entorno cambiante.

Los nexos de la Sociología con la problemática de la racionalidad, a juicio del autor, resultan imposibles de cortar en tanto que esta ciencia tiene que vérselas con tres órdenes de problemas: a) empíricos, en tanto que, como ciencia de la sociedad burguesa, se ocupa de los procesos de racionalización que en ella tienen lugar, y desde esta perspectiva estudia los procesos de crisis de las formas tradicionales de vida; b) lo anterior remite a aspectos metateóricos, es decir, a los fundamentos racionales de sus propuestas teóricas para la comprensión de la acción social y, finalmente, c) a problemas metodológicos relacionados con las particularidades del acceso a su objeto de estudio en términos de comprensión y explicación, es decir, de las relaciones entre el significado y la validez de las expresiones simbólicas que estructuran los mundos socioculturales de la vida. 
Habermas señala que estos son precisamente los temas que ocuparon la actividad intelectual de Max Weber. Sobre estas bases se pronuncia por un trabajo conjunto entre Filosofía y Sociología: la razón, el tema fundamental de la Filosofía, ya no puede ser resuelto por la vía de encontrar fundamentos últimos, sino que demanda conectarse con "los análisis empíricos de la materialización y evolución histórica de las estructuras de la racionalidad" (Habermas, 1999: vol. I, p. 17), el tema de la Sociología.

Si encontramos que ha cobrado realidad el designio de Weber, según el cual los procesos de racionalización de la vida moderna conducían inexorablemente a que el espíritu, la libertad, quedara encapsulada en el férreo estuche de la racionalidad con arreglo a fines; a que, en los términos de Horkhaimer y Adorno, la Ilustración se tornara en mitología; a que, conforme a los planteamientos de Lucaks, se comprenda que racionalidad instrumental y cosificación son dos caras de la misma moneda, entonces ¿podemos concluir que la modernidad es un proyecto agotado?, ¿fue tan solo una ilusión en la que tras la máscara de la razón se ocultaban las pretensiones de poder?, ¿no queda otro camino que reconocer el imperio de la tradición y de los poderes colectivos sobre las posibilidades de emancipación y de afirmación del individuo autónomo?

Sabemos también que las respuestas a estos interrogantes ya no resultan viables sobre las bases de una filosofía de la conciencia, en tanto que al establecer su fundamento en las relaciones sujeto-objeto conduce inexorablemente a la instrumentalización de la naturaleza externa e interna y de las relaciones sociales, de tal manera que sobre sus bases resulta imposible explicar qué significa la instrumentalización de las relaciones sociales e intrapsíquicas, vista desde la perspectiva de la vida violentada y deformada.

Precisamente, es aquí donde se apoya Habermas para plantear la necesidad de renovación teórica de la Sociología, para encontrar un modelo de explicación que posibilite la comprensión ya no solo desde un sujeto que conoce e interviene en el mundo, sino desde la perspectiva de la vida violentada y deformada. Por eso su recurso a la filosofía del lenguaje, porque este tiene como telos inmanente el entendimiento.

Una teoría sociológica de estas características, sostiene el autor, podrá permitir explicar y comprender los desvíos de los procesos de racionalización, las patologías de las formas de vida moderna, a la vez que vislumbrar alternativas para retomar 
con renovadas energías el proceso de emancipación, de progreso de la autonomía individual en un ambiente social en el que impere la dignidad humana, la libertad, y en el que la naturaleza externa no sea percibida como simple objeto de manipulación o de control.

En esta dirección, Habermas parte de retomar los conceptos de acción y de conocimiento para replantearlos en términos comunicativos. El saber tiene una estructura proposicional, las manifestaciones lingüísticas encarnan un saber tanto sobre estados de cosas en el mundo como sobre los medios y la normas de acción prácticas (instrumentales) para la consecución de determinados fines. En los dos casos, dicho saber puede ser cuestionado como falible y, ante la crítica, es posible exponer razones para justificar lo afirmado.

Esto es precisamente lo que Habermas propone entender como racional: el saber encarnado en manifestaciones lingüísticas, las expresiones lingüísticas mismas y las personas que hacen uso de dichas manifestaciones o expresiones. Resultan ser racionales en tanto que son susceptibles de crítica y de fundamentación, podemos exponer razones tanto para controvertir las afirmaciones como para justificarlas.

La racionalidad puede ser planteada en términos empiristas, es decir, acudiendo a aquella tradición que concibe que nuestro conocimiento está referido a la afectación de los objetos sobre el sujeto cognoscente y que postula la imposibilidad de un conocimiento universal, que trascienda las particulares condiciones en que está puesto el ser humano. A esta orientación, que denomina realista, Habermas opone aquella que sostiene que el sujeto cognoscente no es un mero ente pasivo que percibe y manipula objetos, sino que, además, los organiza y estructura sobre la base de sus propias facultades.

Conservando estos elementos kantianos, Habermas acude a la fenomenología para mostrar cómo desde esta perspectiva se pregunta por las condiciones socio-culturales que determinan las formas de comprender y explicar el mundo, es decir, busca superar el sujeto trascendental kantiano de carácter monológico.

Frente al realista, que presupone la existencia de un mundo objetivo cuyo conocimiento se halla encarnado en las manifestaciones y expresiones lingüísticas, el fenomenólogo se pregunta por las condiciones formales del conocimiento, por los requisitos que hacen posible que un grupo humano comparta el reconocimiento de uno y el mismo mundo: "El mundo sólo cobra objetividad por el hecho de ser reconocido y 
considerado como uno y el mismo mundo por una comunidad de sujetos capaces de lenguaje y acción. El concepto abstracto de mundo es condición necesaria para que los sujetos que actúan comunicativamente puedan entenderse entre sí sobre lo que sucede en el mundo o lo que hay que producir en el mundo" (Habermas, 1999: vol. I, p. 30).

Las condiciones que permiten que el mundo pueda ser reconocido y considerado como uno y el mismo mundo por una comunidad de sujetos es lo que Habermas comprende como mundo de la vida y, como podrá advertirse, tiene un carácter intersubjetivo. Así, la labor del sociólogo se ve ante un doble esfuerzo: por un lado, comprender las condiciones (intersubjetivas) que hacen posible que una comunidad reconozca uno y el mismo mundo y, por el otro, establecer de qué manera los paradigmas o esquemas teóricos de los que hace uso el investigador permiten hacer comprensible el conocimiento de dichas comunidades. Esta duplicación de los esfuerzos es lo que Giddens llama la doble hermenéutica:

La mediación de paradigmas o de esquemas teóricos ampliamente divergentes en la ciencia es una tarea hermenéutica como la que exigen los contactos entre otros tipos de marcos de sentido. Pero la sociología, a diferencia de la ciencia natural, se ocupa de un mundo preinterpretado, donde la creación y reproducción de los marcos de sentido es la condición misma de lo que procura analizar, o sea, una conducta social humana: por esto, lo repito, existe una hermenéutica doble en las ciencias sociales (Giddens, 2001, pp. 190-191).

Establecido que Habermas no se refiere a una racionalidad en términos empiristas, sino que busca establecer sus condiciones formales, retomemos las distintas expresiones de la racionalidad. En tanto que ya no es posible encontrar un fundamento último para nuestro saber, sin que ello implique que no sea susceptible de crítica y de justificación, podemos reconocer que las manifestaciones y expresiones lingüísticas encarnan un saber falible y, en consecuencia, remite a determinadas pretensiones de validez.

En lo antes expuesto, reconocemos dos de tales pretensiones: la verdad y el éxito o la eficacia. Con la primera nombramos los procesos comunicativos en los que sometemos a crítica y fundamentación el saber que se refiere a los estados de cosas que suceden en el mundo; con la segunda, a aquellos que hacen referencia a los medios y las normas instrumentales de acción que conducen al logro de un fin determinado, y también, a la discusión sobre el fin propuesto, es decir, sobre el estado de cosas que se desea producir. 
Hasta aquíHabermas no ha hecho otra cosa que redefinir, sobre bases comunicativas, con los tipos de racionalidad que ya nos son familiares: la acción racional con arreglo a fines y el conocimiento científico-instrumental; además, indica que la forma de argumentación propia de estos ámbitos del saber es el discurso teórico. No obstante, el propósito de Habermas es aprehender el conjunto de la vida social, mostrar cómo a las distintas esferas de valor que en la modernidad se separan, y que Weber describe, les subyacen estructuras racionales.

Para ello el autor muestra que tanto las normas, las vivencias subjetivas, los valores y las mismas manifestaciones lingüísticas son susceptibles de racionalización, es decir, de crítica y fundamentación, si bien ateniéndose a parámetros propios en cada una de dichas esferas. Así, muestra cómo la racionalización de las normas pone en discusión la rectitud tanto de los comportamientos interpersonales como la de las normas mismas. Esta discusión lleva aneja una pretensión de validez que es la rectitud de las normas morales y jurídicas, es decir, sobre las relaciones intersubjetivas que son o pueden considerarse legítimas. La forma de argumentación, en este caso, es el discurso práctico.

Por su parte, lo que se pone en cuestión, lo que es susceptible de racionalización en elámbito de la vivencias subjetivas a las que el actor tiene un acceso privilegiado, es la veracidad de sus expresiones; la pretensión de validez que hace referencia a la veracidad puede ser criticada y justificada en tanto expresión veraz de estados subjetivos, de la naturaleza interna. La forma de argumentación de este saber es la crítica terapéutica.

Los valores propios de cada cultura son susceptibles de crítica y de fundamentación desde el punto de vista de su autenticidad, es decir, de la adecuación a los estándares de valor de un cultura particular; la pretensión de validez es aquíla de adecuación, y, en tanto que está circunscrita a una cultura determinada, no logra los niveles de universalidad de las antes referidas y su forma de argumentación adquiere el carácter de crítica estética.

Finalmente, la inteligibilidad o corrección de los productos simbólicos asume la forma de discurso explicativo y hace referencia al análisis de las manifestaciones y expresiones lingüísticas que constituyen la acción comunicativa.

Como podrá apreciarse, Habermas muestra que cada una de las esferas de la vida cultural, así como el conjunto de la vida socio-cultural misma son susceptibles de 
racionalización y, en consecuencia, de comprensión y explicación racional; con ello amplía el horizonte conceptual de una racionalidad entendida en términos instrumentales. Además, muestra cómo estos conceptos formales requieren ser complementados con otro: el de mundo de la vida.

Sobre estas bases, la crisis de la razón, comprendida en términos de cosificación, de mitificación, de instrumentalización o de cualquier otra perspectiva, así como las posibles alternativas a ella, son asuntos en discusión, y no solo por aquellos que han hecho de los asuntos humanos su objeto de estudio, sino por los partícipes mismos de la construcción social de la realidad, en general, y especialmente por aquellos que han sido objeto de una vida violentada y deformada.

\section{REFERENCIAS}

Aristóteles de Estagira. (2002). La política. Bogotá: Panamericana.

Bacon, F. (1984). Novum Organon. Barcelona: Orbis.

Giddens, A. (2001). Las nuevas reglas del método sociológico: crítica positiva de las sociologías comprensivas. Buenos Aires: Amorrortu.

Habermas, J. (1989). El Discurso Filosófico de la Modernidad. Madrid: Taurus.

Habermas, J. (1999). Teoría de la Acción Comunicativa. Madrid: Taurus.

Homero (1974). La odisea. Barcelona: Bruguera.

Horkheimer, M. \& Adorno, T. (1994). Dialéctica de la Ilustración. Madrid: Trotta.

Hoyos Vásquez, G. y Vargas Guillén, G. (1997). La teoría de la Acción comunicativa como nuevo paradigma de investigación en las ciencias sociales. Bogotá: ICFES, ASCUN.

Hoyos Vásquez, G. (2011). Lo intereses de la vida cotidiana y las ciencias. Kant, Husserl, Habermas. Bogotá: Universidad Nacional de Colombia.

Husserl, E. (1935). 'La filosofía en la crisis de la humanidad europea”. En: Husserl, E. (1969). La filosofía como ciencia estricta. Buenos Aires: Nova.

Kant, I. (1984). Crítica de la Razón Pura. Buenos Aires: Orbis. 
Kant, I. (1986). Fundamentación de la metafísica de las costumbres. México: Porrúa.

Lukács, G. (1985). Historia y consciencia de clase. Barcelona: Orbis.

Marx, C. (1977). El Capital. Bogotá: Fondo de Cultura Económica.

Rojas Rojas, C. E. (2003). Bosquejo de respuesta a la pregunta ¿Qué es la Sociología? Revista Universidad de Caldas, Vol. 23, N. ${ }^{\circ}$ 1. Manizales: Universidad de Caldas.

Rojas Rojas, C. E. (2007). Conflictos morales y derechos humanos en Colombia. Manizales: Editorial Universidad de Caldas.

Weber, M. (1991). La ética protestante y el espíritu del capitalismo, 9 ed. México: Premia editora. 